\title{
OPTIMAL INVENTORY STRATEGIES FOR DETERIORATING ITEMS WITH PRICE-SENSITIVE INVESTMENT IN PRESERVATION TECHNOLOGY
}

\author{
Priyamvada, Rini And Chandra K. JaGgi*i]
}

\begin{abstract}
With recent developments in the technological world, the issue of deterioration has been addressed efficiently through preservation technology by numerous researchers. The fundamental concept of preservation technology involves an investment that is majorly dependent on the initial deterioration rate, irrespective of the selling price of the product. Owing to this, two different products having the same deterioration rate but different selling price requires equal investment, which is irrational. Further, the investment in preservation technology was considered to be per unit time irrespective of the number of units being held, which is again a major drawback of the existing literature. Thus, this paper attempts to bridge the gap by proposing a realistic way of implementing preservation technology, where not only the investment is per unit, but also depends on the selling price of that unit. The model jointly optimizes the selling price, the fraction of per unit profit to be invested in preservation technology, and cycle length to maximize the overall profit. The proposed model proves out to be economically more viable, through superior cost management, when compared with the existing model. The model is further illustrated with comparative numerical examples and graphical representations. Moreover, sensitivity analysis is performed to convey model characteristics.
\end{abstract}

Mathematics Subject Classification. 90B05, 90B30.

Received May 30, 2020. Accepted February 5, 2022.

\section{INTRODUCTION}

Deterioration which is defined as the decay, vaporization, damage or spoilage, brings a change in the product's characteristics that refrains its usage as intended originally. For decades, deterioration of products like perishable foods, several chemicals, electronics, photographic films, drugs and pharmaceuticals, radioactive substances, flowers etc., has been studied by numerous researchers. Moreover, in inventory literature, deteriorating items have been classified as one of the four major divisions Andriolo et al. [2]. With increased business horizons and boom of e-commerce among customers, there is an emerging requirement of such items to be transported over vast geographic areas. Consequently, the optimum dealing of deteriorating products has a lot of potential in order to attain a cost-effective, efficient supply chain. Not to mention, management of deteriorating items poses an additional constraint for the seller to maintain profitability. For instance, food spoilage in Australia costs about $\$ 10000000$ annually in its food sectors as mentioned in Pitt and Hocking [32].

Keywords. Deterioration, Price-sensitive investment in preservation technology, Price-sensitive demand.

Department of Operational Research, Faculty of Mathematical Sciences, University of Delhi, Delhi 110007, India.

* Corresponding author: ckjaggi@yahoo.com 
Furthermore, with easy availability of the same product through many vendors, customers do not compromise with the quality. Also, with increased availability of processed and ready to eat food, there is a need to keep them fresh for a longer duration. Thus, the seller faces the challenge of delaying the process of decay to the maximum extent possible. The loss incurred due to deterioration can be significantly controlled through an investment in preservation technology. A study by Ullah et al. [38] depicted a reduction of total supply chain cost by $13 \%$ and solid waste from deterioration, owing to preservation technology. Numerous researchers have incorporated the implementation of preservation technology in their practical models. Yet most of the research till date considered the investment in preservation technology dependent on initial deterioration rate, independent of per unit profit (hence selling price) of the product. The traditional function which has been widely used by most of the researchers is

$$
\lambda(\beta)=\lambda_{0} e^{-\delta \beta}
$$

where $\lambda_{0}$ is the deterioration rate without preservation technology, $\delta$ is the sensitive parameter of investment in preservation technology to the deterioration rate, $\beta$ is the investment per unit time in preservation technology and $\lambda(\beta)$ is the reduced deterioration rate after investment in preservation technology. Thus, two different products having same deterioration rate but considerable difference in per unit profit requires equal investment in preservation technology, which is illogical. Further, the investment in preservation technology till now has been considered per unit time irrespective of the product type or the number of units being held which again is inconceivable. The presented paper aims to overcome both the pre-mentioned shortcomings and quantifies its impact on profitability which is the ultimate motive of any business scenario. A novel model including a price dependent, per unit preservation investment is implemented and investigated.

Also, it is well known that the demand for a product is highly dependent on its selling price. Therefore, price dependent demand has been assumed in this paper. Subsequently, effective pricing strategies act as a key factor towards increasing market share and adding to customer satisfaction. Consequently, deciding the optimal price is one of the primary concerns for the manufacturer. Thus, this paper considers the selling price as a decision variable along with cycle time and proportion of per unit profit to be invested in preserving a unit.

The remaining paper takes the following structure: Section 2 provides a literature review of the fore mentioned phenomena. Section 3 presents the notations and assumptions for the developed model. Section 4 includes the mathematical model for the inventory system. Section 5 addresses the optimality of formulated inventory model. Section 6 illustrates the proposed inventory model with the help of numerical examples. Section 7 provides the comparison between the proposed way of preservation technology with the classical one. Section 8 explores the sensitivity of optimal solution with respect to various parameters. Section 9 concludes the paper along with an outlook to future research directions.

\section{LiteratuRE REVIEW}

Management of inventory items which are deteriorating in nature has been challenging and attracted researchers' attention for decades. Deterioration is a phenomenon which leads to a financial loss for any industry experiencing it. At the same time, it is a natural and unavoidable process. Thus, strategic decisions to circumvent the mentioned loss and its effect under various real-life scenarios have been of great interest during management of operations. The very first research with deteriorating items was carried out by Ghare and Schrader [7] for exponentially deteriorating items. Later, Jaggi and Aggarwal [10] studied the optimum ordering policy for deteriorating items under the assumption of trade credit by implementing discounted cash-flow (DCF) method. Aggarwal and Jaggi [1] explored the effect of permissible delay in payments on optimum ordering policy for deteriorating items. Recently, Jaggi et al. [16] demonstrated optimum credit policies for deteriorating items under the assumptions of imperfect items, exponentially increasing demand and partial backlogging. Also, Mandal et al. [22] proposed an inventory model with deteriorating items under the assumption of Geometric Programming. Later, Panda et al. [29] developed an inventory model for a seasonal product with ramp-type demand. Min et al. [25] proposed an inventory model for the deteriorating items with stock-dependent demand and two-level trade credit. An extensive review of inventory models with deteriorating items can be referred to 
in Li et al. [20] and Bakker et al. [3]. Some of the decent work on deterioration worth mentioning here includes Jaggi et al. [12], Khanna et al. [18] and Jaggi et al. [11]. Further, Jaggi et al. [14] established optimal policy for deteriorating and imperfect items considering a two-warehouse scenario. Mishra [26] analysed controllable probabilistic deterioration with shortages. Also, Jaggi et al. [15] studied non-instantaneous deterioration with two-warehouses and price-dependent demand. A thorough literature review of deteriorating models segregated by key topics for years 2012 to 2015 has been published by Janssen et al. [17]. Pervin et al. [31] studied a replenishment scenario for a deteriorating item under the assumptions of time-dependent demand, time-dependent holding cost along with shortages. Daryanto et al. [5] examined a sustainable three-tier inventory model for deteriorating items. Shaw et al. [36] investigated an integrated model considering deterioration, carbon emissions and multi-stage inspection while implementing single-setup multi-delivery (SSMD) policy for the delivery of good products.

Since deterioration results in monetary loss, the organization looks out for certain measures to control the loss. One such tool to deal with deterioration effectively is to implement preservation technology techniques to increase the life span of deteriorating products. Although investment in preservation technology contributes to the cost component, yet it will minimize the total cost by reducing the loss due to deterioration. To maintain the usability of the product Hsu et al. [9] proposed an inventory model with constant demand rate and preservation technology investment. Singh and Sharma [37], Hsieh and Dye [8] worked on two-stage production models with preservation technology. Bardhan et al. [4] studied the optimal replenishment policy for a non-instantaneously deteriorating item under the assumption of stock- dependent demand. Mishra et al. [27] introduced an EOQ model with preservation technology under the assumption of trade credit. Li et al. [21] considered an optimizing inventory scenario for non-instantaneous deteriorating items with investment in preservation technology, optimum pricing and replenishment. Recently, Mishra et al. [28] proposed a replenishment model for a noninstantaneous deteriorating item considering preservation technology and sustainability. Their analysis through a case study on greenhouse flower retailer suggested enhanced financial performance with a continuous investment in preservation technology and emission cost. Das et al. [6] explored the impact of preservation on a non-instantaneous deteriorating item considering two different preservation rates and two different backlogging rates. Mashud et al. [24] explored the usage of preservation technology along with credit financing for the reduction of deterioration rate to provide flexible financing to customers. Further, Mashud et al. [23] studied the scenario of non-instantaneously deteriorating inventory, assuming partially backlogged shortages, price and advertisement dependent demand under the effect of preservation technology and credit financing.

Further, it is well known that one factor with immense influence on the demand is the selling price. Thus, selling price dependent demand has great significance in practical models. Sana [33] developed an EOQ model where the demand decreases quadratically with price. Some of the models considering price-sensitive demand are Khanna et al. [19], Wang and Lin [39], Xiao and Xu [40], Zhang et al. [42] etc. Jaggi et al. [13] studied the problem of credit-financing for a deteriorating product under the assumption of price-sensitive demand. Saha and Goyal [34] proposed three different supply chain coordination contracts with price dependent demand. Panda et al. [30] introduced a volume flexible inventory model for a deteriorating item whose demand is dependent on the selling price. Some other recent works including price-dependent demand include Li et al. [21], Das et al. [6], Shaikh et al. [35] etc. Table 1 provides a summary of related research.

To the best of authors' knowledge, previous studies implementing a functional form of preservation technology investment to control deterioration rate, have neglected two important aspects:

(1) Practically, the optimal investment in preservation technology should not be just based on the deterioration rate. It basically implies the requirement of equal investment for two products having different selling price and thus per unit profit, which cannot be optimal in both the cases. Therefore, investment in preservation technology based on both its selling price (and thus on unit profit) and deterioration rate is more feasible and is the strong suit of this paper.

(2) Considering the preservation technology cost per unit time is not conceivable for all kinds of deteriorating products. This is due to the fact that methods of preserving different items are different; say, some chemicals or food items require special packaging to curb the deterioration rate, other items require specific 
TABLE 1. Summary of related research.

\begin{tabular}{lllll}
\hline Authors & $\begin{array}{l}\text { Price- } \\
\text { sensitive } \\
\text { demand }\end{array}$ & Deterioration & $\begin{array}{l}\text { Traditional } \\
\text { preservation } \\
\text { technology }\end{array}$ & $\begin{array}{l}\text { Price-based } \\
\text { preservation } \\
\text { technology }\end{array}$ \\
\hline Sana [33] & $\checkmark$ & $\checkmark$ & $\times$ & $\times$ \\
Jaggi et al. [15] & $\checkmark$ & $\checkmark$ & $\times$ & $\times$ \\
Saha and Goyal [34] & $\checkmark$ & $\times$ & $\times$ & $\times$ \\
Hsu et al. [9] & $\times$ & $\checkmark$ & $\checkmark$ & $\times$ \\
Panda et al. [30] & $\checkmark$ & $\checkmark$ & $\times$ & $\times$ \\
Li et al. [21] & $\times$ & $\checkmark$ & $\checkmark$ & $\times$ \\
Mishra et al. [27] & $\checkmark$ & $\checkmark$ & $\checkmark$ & $\times$ \\
Wang and Ling [39] & $\checkmark$ & $\checkmark$ & $\times$ & $\times$ \\
Das et al. [6] & $\checkmark$ & $\checkmark$ & $\checkmark$ & $\times$ \\
Zhang et al. [41] & $\checkmark$ & $\checkmark$ & $\checkmark$ & $\times$ \\
This Paper & $\checkmark$ & $\checkmark$ & $\checkmark$ & $\checkmark$ \\
\hline
\end{tabular}

machinery for receiving (temperature conditions to avoid microbial growth) and storing items under a specific required environment, items like flowers require techniques like hot air drying, silica gel drying, molecular sieving etc., techniques like food irradiation being used for increasing the shelf life of some products, some retailers may implement multi-stage inspection for sorting heavily deteriorated items from the whole lot as heavily deteriorated products can catalyze the deterioration of other fresh items. For all the cases, per unit investment in preservation technology is more logical.

In view of this, this research paper is a breakthrough in introducing price-sensitive preservation technology investment per unit. It has been assumed that a fraction of per unit profit is invested in preserving one unit. Further, demand is assumed to be a function of price. Under this scenario, the proposed study aims to jointly optimize the fraction of per unit profit, selling price and order replenishment cycle time.

\section{NotATIONS AND ASSUMPTIONS}

In this section, the notations and assumptions used throughout the paper are established.

\subsection{Notations}

Following notations are used to develop the model. For better comprehension, four categories have been formed: Decision variables, dependent decision variable, constant parameters, and functions.

\section{Decision variables}

$p$ : $\quad$ Selling price per unit

T: $\quad$ Order replenishment cycle time

$\alpha$ : $\quad$ Fraction of per unit profit

\section{Dependent decision variable}

$Q$ : Order quantity

\section{Constant parameters}

$y_{0}: \quad$ Rate of deterioration without preservation technology

a: $\quad$ Constant demand parameter

$b$ : $\quad$ Scaling parameter of demand

c: Unit purchase cost 
$h$ : $\quad$ Inventory carrying cost per unit per unit time

$K$ : $\quad$ Ordering cost per order

\section{Functions}

$D(p): \quad$ Demand rate dependent on price

$y(p, \alpha)$ : $\quad$ Rate of deterioration with preservation technology

$I(t): \quad$ Inventory level at time $t$

$\operatorname{TP}(T, p, \alpha)$ : Total profit per unit time

\subsection{Assumptions}

The proposed model is developed under the assumptions adopted from Zhang et al. [41] except the function of preservation technology used.

(i) The demand rate is continuous and dependent on the selling price, i.e.,

$$
D(p)=a-b p \text {, where } a, b>0 .
$$

(ii) Deterioration rate is constant throughout the cycle.

(iii) Continuous review system is in place.

(iv) Planning horizon is infinite.

(v) Lead time is negligible.

(vi) EOQ lot-sizing inventory replenishment policy is considered where replenishment is instantaneous.

(vii) Preservation technology investment reduces the rate of deterioration with a function

$$
y(p, \alpha)=y_{0} e^{-(p-c)^{2} \alpha}
$$

which is convex in nature (proof is given in Appendix A) with

$$
0<\alpha<1, p>0 \text { and } y(p, 0)=y_{0} .
$$

(viii) The inventory level depletes under the combined effect of demand and deterioration, which attains the level zero at the end of the inventory cycle (refer to Fig. 1).

(ix) The selling price is greater than the unit purchase cost, $p>c$.

(x) Shortages are not allowed.

\section{Mathematical MODEL}

The inventory in the considered system is depleting due to demand as well as deterioration. A price-dependent investment in preservation technology abates the original deterioration rate to a considerable extent, thereby decreases the inventory depletion due to deterioration. This behavior of the inventory system is illustrated in Figure 1.

The differential equation representing the inventory level is

$$
\frac{\mathrm{d}(I(t))}{\mathrm{d} t}+y(p, \alpha) I(t)=-(a-b p), \quad 0 \leq t \leq 1 .
$$

Considering the boundary condition $I(T)=0$, the solution of equation (4.1) is given as:

$$
I(t)=\frac{D(p)}{y(p, \alpha)}\left[e^{y(p, \alpha)(T-t)}-1\right] .
$$

The initial inventory level is computed with

$$
Q=I(0)=\frac{D(p)}{y(p, \alpha)}\left[e^{y(p, \alpha) T}-1\right] .
$$




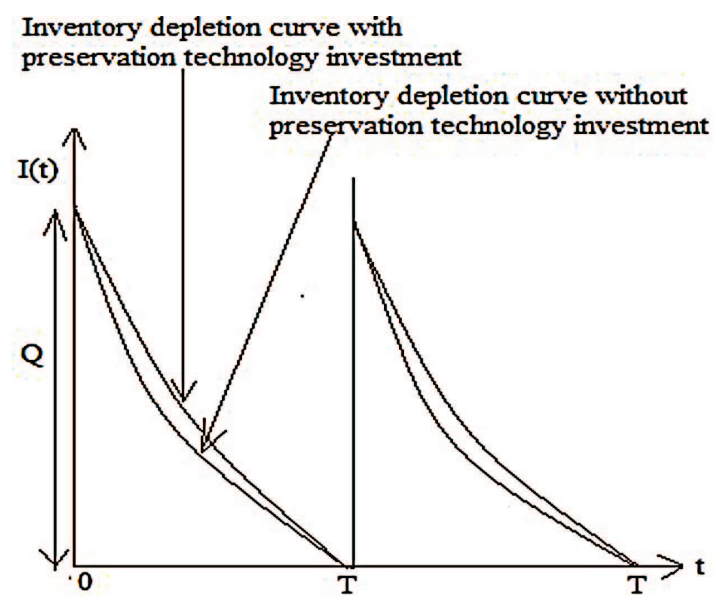

FIGURE 1. Inventory flow representation.

The total number of items which are deteriorated during the total cycle time $T$, say $D_{T}$, is calculated as

$$
D_{T}=Q-D(p) T=\frac{D(p)}{y(p, \alpha)}\left[e^{y(p, \alpha) T}-1\right]-D(p) T .
$$

The total cost for the system per unit cycle time can be computed with the help of the following cost components

(i) Holding Cost $=\frac{h}{T} \int_{0}^{T} I(t) \mathrm{d} t=\frac{h D(p)}{T(y(p, \alpha))^{2}}\left[e^{y(p, \alpha) T}-T(y(p, \alpha))-1\right]$

(ii) Ordering Cost $=\frac{K}{T}$

(iii) Purchase Cost $=\frac{c}{T} Q=\frac{c D(p)}{T y(p, \alpha)}\left[e^{y(p, \alpha) T}-1\right]$

(iv) Preservation Technology Cost $=\frac{(p-c) \alpha}{T} Q=\frac{(p-c) \alpha D(p)}{T y(p, \alpha)}\left[e^{y(p, \alpha) T}-1\right]$.

Hence, the total cost of the system will be

$$
\begin{aligned}
\operatorname{TC}(T, p, \alpha)= & \frac{h D(p)}{T y(p, \alpha)^{2}}\left[e^{y(p, \alpha) T}-T(y(p, \alpha))-1\right]+\frac{K}{T} \\
& +\frac{c D(p)}{T y(p, \alpha)}\left[e^{y(p, \alpha) T}-1\right]+\frac{(p-c) \alpha D(p)}{T y(p, \alpha)}\left[e^{y(p, \alpha) T}-1\right] .
\end{aligned}
$$

Total revenue of the system will be

$$
\operatorname{TR}(p)=p D(p)
$$

Total profit of the system will be

$$
\operatorname{TP}(T, p, \alpha)=\operatorname{TR}(p)-\operatorname{TC}(T, p, \alpha) .
$$

i.e.,

$$
\operatorname{TP}(T, p, \alpha)=p D(p)-\frac{h D(p)}{T y(p, \alpha)^{2}}\left[e^{y(p, \alpha) T}-T(y(p, \alpha))-1\right]-\frac{K}{T}
$$




$$
-\frac{c D(p)}{T y(p, \alpha)}\left[e^{y(p, \alpha) T}-1\right]-\frac{(p-c) \alpha D(p)}{T y(p, \alpha)}\left[e^{y(p, \alpha) T}-1\right] .
$$

Further, it can be easily realized from equation (4.12) that the proposed model is reducible to Zhang et al. [41], whose profit function is given by equation (4.13), by interchanging the expression of $\frac{(p-c) \alpha D(p)}{T y(p, \alpha)}\left[e^{y(p, \alpha) T}-1\right]$ by $u$ (preservation technology cost) and the corresponding $y(p, \alpha)$ by $\theta(1-f(u))$ (reduced deterioration rate).

$$
\begin{aligned}
\Pi(T, p, u)= & p D(p)-\frac{h D(p)}{T \theta^{2}(1-f(u))^{2}}\left[e^{T \theta(1-f(u))}-T \theta(1-f(u))-1\right]-\frac{K}{T} \\
& -\frac{c D(p)}{T \theta(1-f(u))}\left[e^{T \theta(1-f(u))}-1\right]-u .
\end{aligned}
$$

\section{Optimality}

The objective of the study is to maximize the profit by jointly optimizing the order replenishment cycle time $(T)$, the fraction of investment in preservation technology $(\alpha)$, and selling price $(p)$.

Now simplifying and expanding $e^{y(p, \alpha) T}$ and ignoring the second and higher powers of $y(p, \alpha) T$ as $y(p, \alpha) T \ll 1$ in equation (4.12) reduces to

$$
\begin{aligned}
\operatorname{TP}(T, p, \alpha)= & p D(p)-\frac{h D(p) T}{2}-\frac{K}{T}-c D(p)-\frac{c D(p) y(p, \alpha) T}{2} \\
& -(p-c) \alpha D(p)-\frac{(p-c) \alpha D(p) y(p, \alpha) T}{2}
\end{aligned}
$$

Necessary conditions for optimality are:

$$
\begin{aligned}
& \frac{\partial \mathrm{TP}}{\partial T}=0, \frac{\partial \mathrm{TP}}{\partial p}=0, \frac{\partial \mathrm{TP}}{\partial \alpha}=0 \\
& \frac{\partial \mathrm{TP}}{\partial T}=\frac{-D(p) h}{2}+\frac{K}{T^{2}}-\frac{c D(p) y(p, \alpha)}{2}-\frac{(p-c) \alpha D(p) y(p, \alpha)}{2}=0 .
\end{aligned}
$$

From the equation (5.3), the value of $T$ will be

$$
\begin{aligned}
T= & \sqrt{\frac{2 K}{h D(p)+D(p) y(p, \alpha)(c+p \alpha-c \alpha)}} \\
\frac{\partial \mathrm{TP}}{\partial \alpha}= & \frac{(p-c) T D(p) y(p, \alpha)}{2}(p-1)-(p-c) D(p)=0 \\
\frac{\partial \mathrm{TP}}{\partial p}= & D^{\prime}(p)\left[p-c-\frac{h T}{2}-\frac{c y(p, \alpha) T}{2}-(p-c) \alpha-\frac{(p-c) \alpha y(p, \alpha) T}{2}\right] \\
& +D(p)-\alpha D(p)-\frac{\alpha y(p, \alpha) D(p) T}{2}-\frac{D(p) y^{\prime}(p, \alpha) T}{2}(c+p \alpha-c \alpha)=0 .
\end{aligned}
$$

By solving the equations (5.4)-(5.6) simultaneously, the values of $T, \alpha$ and $p$ can be obtained respectively. The values attained of $T, \alpha$ and $p$ are near optimal (referred to as optimal values in remaining text) due to truncation of higher order terms in Taylor series yet an acceptable approximation to the actual values.

Further, to establish the concavity of the objective function, the sufficient conditions involve hessian matrix of the second derivatives. All the second order derivatives are highly non-linear in nature; therefore, it is difficult to prove the sufficient conditions mathematically with respect to these three variables i.e., T, $\alpha$ and $p$ simultaneously. However, as assumed that $\alpha$ lies between 0 and 1, therefore, by taking $\alpha$ as fixed, optimality with respect to the variables $T$ and $p$ are established through following lemma. 
TABLE 2. Comparison of results with and without preservation technology.

\begin{tabular}{lll}
\hline Optimal values & $\begin{array}{l}\text { With preservation } \\
\text { technology }\end{array}$ & $\begin{array}{l}\text { Without preser- } \\
\text { vation technology }\end{array}$ \\
\hline Total profit $(\mathrm{TP})$ & $\$ 153.83$ & $\$ 128.59$ \\
Cycle time $(T)$ & 1.62 months & 1.00 months \\
Selling price $(p)$ & $\$ 13.18$ & $\$ 13.54$ \\
Fraction per unit profit $(\alpha)$ & 0.021 & 0 \\
\hline
\end{tabular}

Lemma. When fraction $\alpha$ is fixed, the profit function $\operatorname{TP}(T, p, \alpha)$ is concave with respect to the replenishment order cycle time $T$ and the selling price $p$.

Proof. Appendix B.

After substituting the optimal values of $T, \alpha$ and $p$ in equation (5.1), we get the total optimal profit of the system.

\section{NumERICAL ANALYSIS}

This section aims to illustrate the developed model using numerical examples.

Example 6.1. The parametric values, taken from Zhang et al. [41], are as follows:

$$
K=80 / \text { order }, \quad c=5 / \text { unit }, \quad y_{0}=0.5, \quad h=1 / \text { unit/year, } \quad a=100, \quad b=5 .
$$

Optimal results are recorded in the second column of Table 2.

It is evident from these findings that, the investment in preservation technology results in a considerable increase in the total profit of the system.

Example 6.2. If the original deterioration rate is very less, keeping the other parameters same, i.e.,

$$
y_{0}=0.005 \text {. }
$$

The Optimal results are as follows.

The total profit of the system with preservation technology investment, TP $=\$ 204.113$, the replenishment order cycle time $T=2.11$ month, the selling price is $p=\$ 13.04$ and the fraction will be $\alpha=0$.

This indicates that, when the deterioration rate is negligible, no investment in preservation technology is required.

\section{Comparative numerical analysis}

This section aims to compare the presented model with Zhang et al. [41]. The two models differentiate only in the implementation of preservation technology.

The numerical example uses the following data in appropriate units (taken from Zhang et al. [41])

$$
K=80 / \text { order }, \quad c=5 / \text { unit }, \quad y_{0}=0.5, \quad h=1 / \text { unit/year }, \quad a=100, b=5 .
$$

Table 3 compares the results obtained by implementing proposed function of preservation technology with widely used traditional function. If the deterioration rate is high, it is evident from the results that investing an optimal proportion of profit per unit as proposed can be highly beneficial. The optimal ordering quantity 
TABLE 3. Comparison of traditional and proposed function of preservation technology.

\begin{tabular}{|c|c|c|c|}
\hline Initial deterioration rate & Optimal values & $\begin{array}{l}\text { Traditional } \\
\text { function of } \\
\text { preservation } \\
\text { technology } \\
{[41]}\end{array}$ & $\begin{array}{l}\text { Proposed func- } \\
\text { tion of preserva- } \\
\text { tion technology } \\
\text { (This paper) }\end{array}$ \\
\hline \multirow{5}{*}{$\operatorname{High}\left(y_{0}=0.5\right)$} & Total Profit (TP) & $\$ 153.83$ & $\$ 187.56$ \\
\hline & Cycle time $(T)$ & 1.62 months & 2.08 months \\
\hline & Selling price $(p)$ & $\$ 13.18$ & $\$ 13.43$ \\
\hline & Ordering quantity $(Q)$ & 61 units & 70 units \\
\hline & $\begin{array}{l}\text { Preservation technology } \\
\text { investment }\end{array}$ & $\$ 29.276$ & $\$ 13.065$ \\
\hline \multirow[t]{5}{*}{ Moderate $\left(y_{0}=0.05\right)$} & Total profit (TP) & $\$ 195.06$ & $\$ 197.04$ \\
\hline & Cycle time $(T)$ & 1.87 months & 2.03 months \\
\hline & Selling price $(p)$ & $\$ 13.18$ & $\$ 13.17$ \\
\hline & Ordering quantity $(Q)$ & 68 units & 71 units \\
\hline & $\begin{array}{l}\text { Preservation technology } \\
\text { investment }\end{array}$ & $\$ 26.67$ & $\$ 12.16$ \\
\hline \multirow{5}{*}{ Low $\left(y_{0}=0.005\right)$} & Total profit (TP) & $\$ 204.11$ & $\$ 204.11$ \\
\hline & Cycle time $(T)$ & 2.11 months & 2.11 months \\
\hline & Selling price $(p)$ & $\$ 13.04$ & $\$ 13.04$ \\
\hline & Ordering quantity $(Q)$ & 74 units & 74 units \\
\hline & $\begin{array}{l}\text { Preservation technology } \\
\text { investment }\end{array}$ & $\$ 0$ & $\$ 0$ \\
\hline
\end{tabular}

increases along with cycle time as the proposed method is more efficient in controlling the effect of deterioration and products can be stored for a longer duration.

Thus, it can be stated that controlling deterioration by implementing preservation technology in the proposed manner is not only more practical but also beneficial as it brings an increase in total profit in case of deteriorating items with high and moderate deterioration rate.

\subsection{Graphical comparison of both type of investment}

Figures $2-5$ graphically compares the two mentioned preservation technology functions: proposed vs. traditional. The effect of change in demand and cost price on total profit and preservation technology cost for both the functions has been depicted.

\section{SENSITIVITY ANALYSIS}

This section aims to analyze the robustness of the developed model and to figure out which parameters have a significant impact on the optimal policies so that the over or underestimation of these parameters must be avoided. The analysis is carried out by changing the parameter values in the range of $-40 \%$ to $+40 \%$ to study the effect on the optimal values of the selling price $p$, cycle length $T$, the fraction of investment in preservation technology $\alpha$, Total profit per unit time (TP) and lot size $(Q)$. The results are recorded in Table 4.

Basic readings from Table 4, which are self-explanatory, are represented in Table 5.

\section{Managerial insights}

(i) For an efficient supply chain of deteriorating items, the manager should invest in preservation technology as it reduces the overall cost thereby bringing an increase in total profit. This study implies an approximate increase of $20 \%$ in total profit due to investment in preservation technology. 


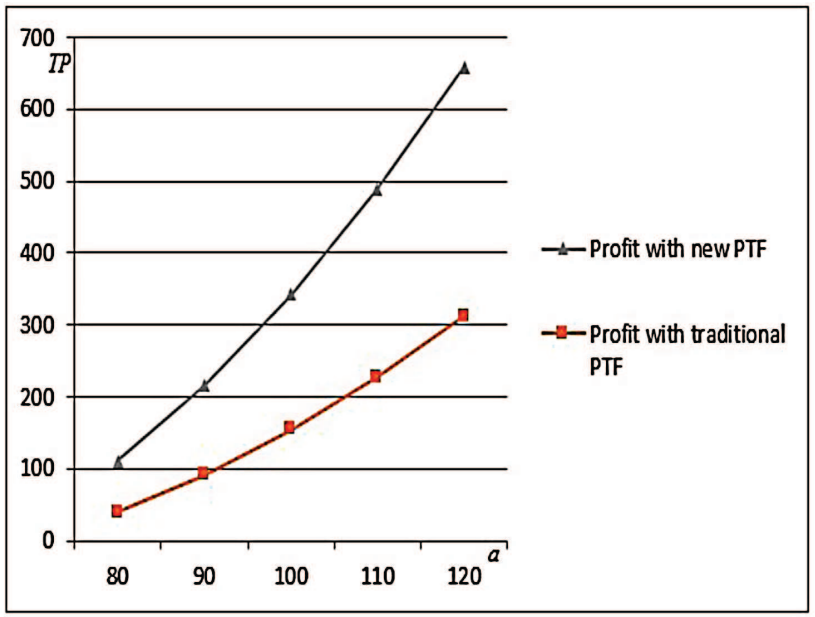

FiguRE 2. Comparative effects of demand parameter on total profit for both investments.

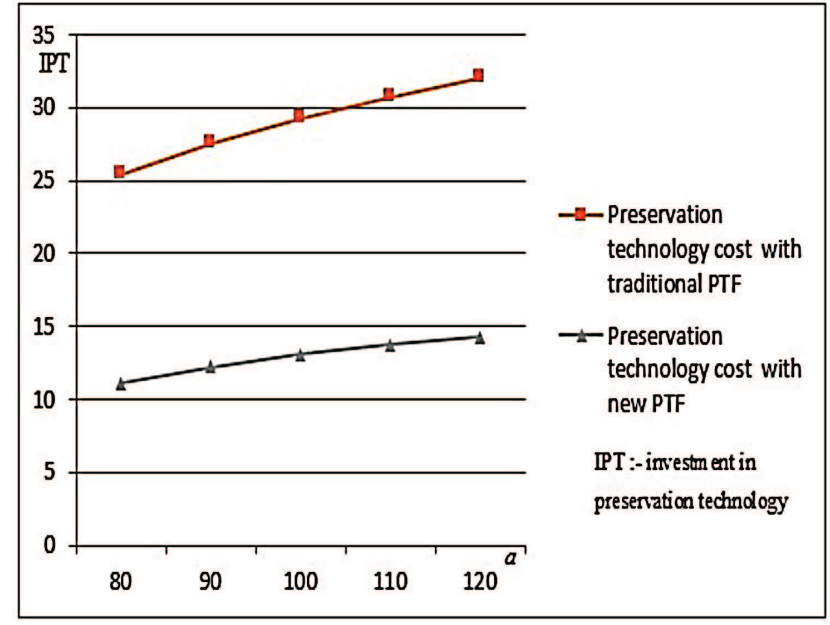

FiguRE 3. Comparative effects of demand parameter on preservation technology cost in both the investments.

(ii) For a significant deterioration rate, investing an optimum fraction of per unit profit to preserve one unit as proposed, against the overall investment per unit time for a specific deterioration rate, is more effective. By doing so, the total investment required in preservation technology reduces with an increase in total profit by $22 \%$ approximately.

(iii) Investment in preservation leads to an increase in optimum cycle time and hence optimal lot size due to a substantial decrease in deterioration. Subsequently, number of orders and thus the overall ordering cost decreases. Therefore, for business scenarios with high ordering cost, an investment in preservation technology proves out to be monetarily beneficial.

(iv) Considering the high sensitivity of total profit to constant demand parameter $a$ and scaling parameter $b$, the decision maker should primarily focus on these while making decisions. Additionally, the effect of unit cost on total profit is also of importance and requires attention. 


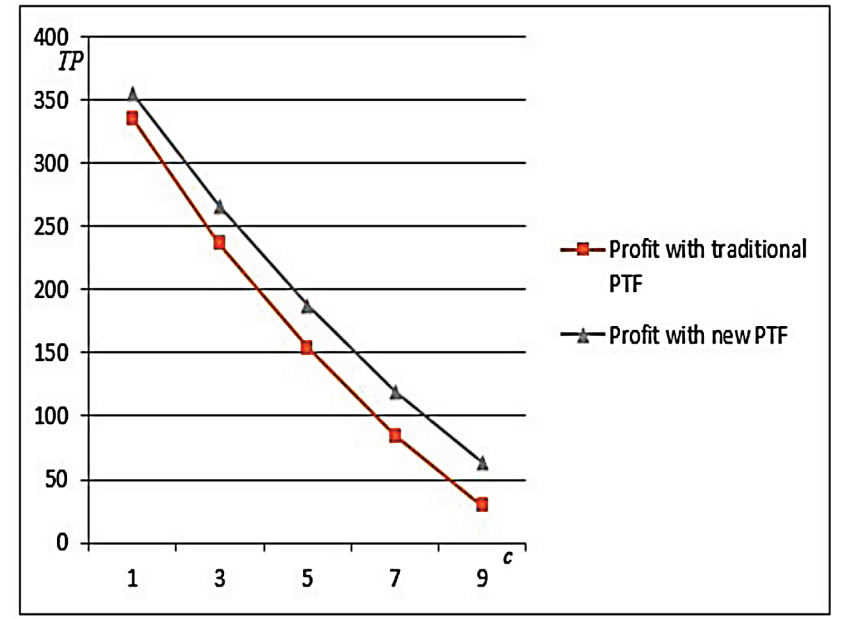

Figure 4. Comparative effects of cost price on total profit for both the investments.

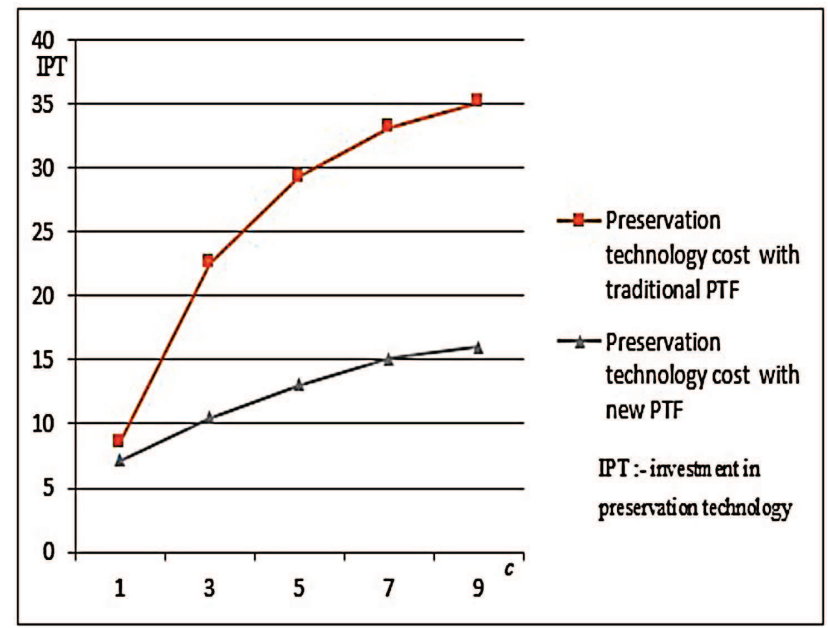

FiguRE 5. Comparative effects of cost price on total profit for both the investments.

(v) While strategizing for optimal pricing, demand of the product plays a considerable role. The manager can take advantage of increased demand by increasing the selling price or strategize for a reduction in selling price in order to boost the demand. Further, a boosted demand implies an increase in optimal replenishment quantity along with a quick flow to the market. Consequently, the investment in preservation technology along with optimum cycle length will experience a reduction.

(vi) A higher holding cost decreases the optimal lot size thereby increasing the ordering cost. In such a case, the decision-maker will have to increase the frequency of orders by ordering fewer units in every order. Subsequently, decreasing the investment in preservation technology. Accordingly, the optimum cycle time decreases thereby decreasing the profit.

(vii) If the unit purchase cost increases, the manager should increase the selling price to avoid losses. Further, to justify the increased selling price the units must be kept in perfect condition; thus, the decision-maker 
TABLE 4. Sensitivity analysis of Example 6.1.

\begin{tabular}{|c|c|c|c|c|c|}
\hline Parameter & $\begin{array}{l}\text { Optimum } \\
\text { values }\end{array}$ & $-40 \%$ & $-20 \%$ & $+20 \%$ & $+40 \%$ \\
\hline \multirow[t]{5}{*}{$a$} & $p^{*}$ & -25.23 & -13.42 & 13.94 & 28.16 \\
\hline & $T^{*}$ & 83.42 & 22.14 & -12.69 & -21.29 \\
\hline & $\alpha^{*}$ & 200.93 & 62.86 & -31.89 & -50.83 \\
\hline & $\mathrm{TP}^{*}$ & -99.52 & -61.91 & 84.58 & 191.29 \\
\hline & $Q^{*}$ & -44.82 & -18.36 & 15.19 & 28.49 \\
\hline \multirow[t]{5}{*}{$b$} & $p^{*}$ & 48.33 & 17.96 & -11.75 & -19.92 \\
\hline & $T^{*}$ & -7.49 & -4.21 & 5.60 & 13.26 \\
\hline & $\alpha^{*}$ & -63.40 & -35.67 & 46.04 & 101.59 \\
\hline & $\mathrm{TP}^{*}$ & 170.46 & 62.81 & -40.16 & -67.14 \\
\hline & $Q^{*}$ & 12.36 & 6.35 & -6.76 & -14.10 \\
\hline \multirow[t]{5}{*}{$h$} & $p^{*}$ & -0.72 & -0.34 & 0.32 & 0.62 \\
\hline & $T^{*}$ & 25.97 & 10.64 & -7.91 & -14.12 \\
\hline & $\alpha^{*}$ & 9.06 & 4.31 & -2.49 & -5.09 \\
\hline & $\mathrm{TP}^{*}$ & 8.27 & 3.88 & -3.52 & -6.76 \\
\hline & $Q^{*}$ & 27.89 & 11.44 & -8.56 & -15.29 \\
\hline \multirow[t]{5}{*}{$c$} & $p^{*}$ & -8.86 & -4.47 & 4.55 & 9.20 \\
\hline & $T^{*}$ & -6.92 & -3.67 & 4.32 & 9.49 \\
\hline & $\alpha^{*}$ & -20.83 & -10.25 & 12.04 & 24.44 \\
\hline & $\mathrm{TP}^{*}$ & 41.86 & 20.22 & -18.79 & -36.14 \\
\hline & $Q^{*}$ & 10.15 & 5.16 & -5.40 & -11.09 \\
\hline \multirow[t]{5}{*}{$K$} & $p^{*}$ & -1.13 & -0.52 & 0.46 & 0.89 \\
\hline & $T^{*}$ & -24.79 & -11.68 & 10.70 & 20.60 \\
\hline & $\alpha^{*}$ & -6.40 & -2.34 & 2.80 & 4.55 \\
\hline & $\mathrm{TP}^{*}$ & 9.40 & 4.36 & -3.90 & -7.45 \\
\hline & $Q^{*}$ & -22.99 & -10.70 & 9.57 & 18.30 \\
\hline \multirow[t]{5}{*}{$y_{0}$} & $p^{*}$ & -0.41 & -0.17 & 0.14 & 0.26 \\
\hline & $T^{*}$ & -0.47 & -0.19 & 0.18 & 0.33 \\
\hline & $\alpha^{*}$ & -14.61 & -6.01 & 5.91 & 10.38 \\
\hline & $\mathrm{TP}^{*}$ & 1.09 & 0.47 & -0.38 & -0.71 \\
\hline & $Q^{*}$ & 0.38 & 0.16 & -0.13 & -0.25 \\
\hline
\end{tabular}

TABLE 5. Basic readings from sensitivity analysis.

\begin{tabular}{llllll}
\hline Increase in parameter & $p^{*}$ & $T^{*}$ & $\alpha^{*}$ & $\mathrm{TP}^{*}$ & $Q^{*}$ \\
\hline$a$ & $\uparrow M$ & $\downarrow M$ & $\downarrow H$ & $\uparrow H$ & $\uparrow M$ \\
$b$ & $\downarrow M$ & $\uparrow L$ & $\uparrow M$ & $\downarrow H$ & $\downarrow L$ \\
$h$ & $\uparrow N$ & $\downarrow M$ & $\downarrow L$ & $\downarrow L$ & $\downarrow M$ \\
$c$ & $\uparrow L$ & $\uparrow L$ & $\uparrow M$ & $\downarrow M$ & $\downarrow L$ \\
$K$ & $\uparrow N$ & $\uparrow M$ & $\uparrow L$ & $\downarrow L$ & $\uparrow M$ \\
$y_{0}$ & $\uparrow N$ & $\uparrow N$ & $\uparrow M$ & $\downarrow N$ & $\downarrow N$ \\
\hline
\end{tabular}

Notes. $\uparrow$ - Increases, $H$ - Highly Sensitive $(50 \%+), L$ - Less Sensitive $(10 \%-), \downarrow-$ Decreases, $M$ - Moderately Sensitive $(15-50 \%), N-$ Negligibly Sensitive $(1 \%-)$.

will have to invest more in preservation technology. An increase in purchase costs would decrease the profit.

(viii) If the ordering cost decreases, the decision maker should order fewer units in one order which will increase the frequency of orders thereby decreasing the cycle time. This will aid in cost saving by decreasing 
the holding cost, thereby increasing the profits. Consequently, the required investment in preservation technology will decrease.

(ix) A high initial deterioration rate implies an increased requirement of preservation technology investment for an optimum reduction of incurred loss due to deterioration.

\section{Conclusion}

Novelty of the presented paper lies in the introduction of an improved, practical way of implementing preservation technology which is price dependent. A simple inventory scenario under the assumptions of deteriorating item and price-sensitive demand has been considered to study the effect of introduced function on the retailer's economic policies. Thus, the proposed study develops an EOQ model for a deteriorating item where demand is dependent on selling price and deterioration rate is controlled by investment in preservation technology. It has been realized that investment in preservation technology proves out to be beneficial as it decreases the loss due to deterioration and increases the total profit by $20 \%$ approximately. The optimality of the profit function has been proved mathematically. Numerical analysis has been performed to validate the model and to compare it with the model having classical function of preservation technology. The results prove that the introduced method has financial dominance on the widely used function of preservation technology, increasing the total profit by $22 \%$ approximately. Thus, the choice of optimum selling price and price dependent investment in preservation technology is more profitable for any business. Thus, this paper altogether provides new dimensions to the implementation of preservation technology for deteriorating items.

The presented research can be extended in several ways, further analyzing the effect of price-based per unit investment in preservation technology. For instance, the model can allow shortages for the cases of complete and partial backlogging. Further, the demand can be considered as seasonal, stock-dependent, advertisementdependent or stochastic. Other possible extensions may include analyzing the effect of non-linear and time dependent holding cost, presence of imperfect items, advance payments, trade credit and inflation on economic policies can be considered. Moreover, the effect on a deteriorating product's life in the scenario of multi-echelon supply chains and multiple inspections can be studied. Inventory parameters may be considered imprecise. Finally, the environmental effects of deterioration and preservation technology can be studied for a sustainable supply chain by incorporating carbon tax, carbon offset policy etc.

\section{Appendix A.}

For the convexity of $y(p, \alpha)$ w.r.t $p$ and $\alpha$,

$$
H=\left[\begin{array}{ll}
\frac{\partial^{2} y(p, \alpha)}{\partial \alpha^{2}} & \frac{\partial^{2} y(p, \alpha)}{\partial \alpha \partial p} \\
\frac{\partial^{2} y(p, \alpha)}{\partial p \partial \alpha} & \frac{\partial^{2} y(p, \alpha)}{\partial p^{2}}
\end{array}\right] \text { and } y(p, \alpha)=y_{0} e^{-\alpha(p-c)^{2}} .
$$

Sufficient conditions for concavity are

$$
\begin{aligned}
\frac{\partial^{2} \mathrm{TP}}{\partial \alpha^{2}}>0 \quad \text { and }\left|\begin{array}{ll}
\frac{\partial^{2} y(p, \alpha)}{\partial \alpha^{2}} & \frac{\partial^{2} y(p, \alpha)}{\partial \alpha \partial p} \\
\frac{\partial^{2} y(p, \alpha)}{\partial p \partial \alpha} & \frac{\partial^{2} y(p, \alpha)}{\partial p^{2}}
\end{array}\right|>0 \\
\frac{\partial^{2} y(p, \alpha)}{\partial \alpha^{2}}=(p-c)^{4} y(p, \alpha)>0 \\
\frac{\partial^{2} y(p, \alpha)}{\partial \alpha \partial p}=\frac{\partial^{2} y(p, \alpha)}{\partial p \partial \alpha}=2(p-c) y(p, \alpha)\left[\alpha(p-c)^{2}-1\right] \\
\frac{\partial^{2} y(p, \alpha)}{\partial p^{2}}=2 \alpha y(p, \alpha)((p-c)-1)
\end{aligned}
$$




$$
\left|\begin{array}{ll}
\frac{\partial^{2} y(p, \alpha)}{\partial \alpha^{2}} & \frac{\partial^{2} y(p, \alpha)}{\partial \alpha \partial p} \\
\frac{\partial^{2} y(p, \alpha)}{\partial p \partial \alpha} & \frac{\partial^{2} y(p, \alpha)}{\partial p^{2}}
\end{array}\right|=4 \alpha^{2}(p-c)^{6}(y(p, \alpha))^{2}+4(p-c)^{2}(y(p, \alpha))^{2}\left[\alpha(p-c)^{2}-1\right]^{2} .
$$

Since $\alpha(p-c)^{2}-1>0$, hence $|H|>0$.

\section{Appendix B.}

For the optimality w.r.t $T$ and $p$, Hessian matrix is needed.

$$
\begin{aligned}
& H=\left[\begin{array}{cc}
\frac{\partial^{2} \mathrm{TP}}{\partial T^{2}} & \frac{\partial^{2} \mathrm{TP}}{\partial T \partial p} \\
\frac{\partial^{2} \mathrm{TP}}{\partial p \partial T} & \frac{\partial^{2} \mathrm{TP}}{\partial p^{2}}
\end{array}\right] \text { and conditions are } \frac{\delta^{2} \mathrm{TP}}{\delta T^{2}}<0 \text { and }\left[\begin{array}{cc}
\frac{\partial^{2} \mathrm{TP}}{\partial T^{2}} & \frac{\partial^{2} \mathrm{TP}}{\partial T \partial p} \\
\frac{\partial^{2} \mathrm{TP}}{\partial p \partial T} & \frac{\partial^{2} \mathrm{TP}}{\partial p^{2}}
\end{array}\right]>0 . \\
& \frac{\partial \mathrm{TP}}{\partial T}=\frac{-D(p) h}{2}+\frac{K}{T^{2}}-\frac{c D(p) y(p, \alpha)}{2}+\frac{(p-c) \alpha D(p) y(p, \alpha)}{2} \\
& \frac{\partial^{2} \mathrm{TP}}{\delta T^{2}}=\frac{-2 K}{T^{3}}<0 \\
& \frac{\partial^{2} \mathrm{TP}}{\partial p \partial T}=\frac{-D^{\prime}(p) h}{2}-\frac{c D^{\prime}(p) y(p, \alpha)}{2}-\frac{c D(p) y^{\prime}(p, \alpha)}{2}-\frac{(p-c) \alpha D^{\prime}(p) y(p, \alpha)}{2} \\
& -\frac{\alpha D(p) y(p, \alpha)}{2}-\frac{(p-c) \alpha D(p) y^{\prime}(p, \alpha)}{2} \\
& \frac{\partial^{2} \mathrm{TP}}{\partial p^{2}}=-b\left[(1-\alpha)+\frac{\alpha y(p, \alpha) T}{2}(c+p \alpha-c \alpha-1)\right]-b(1-\alpha) \\
& -\frac{\alpha b T y(p, \alpha)}{2}(c+p \alpha-c \alpha-1)-\frac{\alpha^{2} D(p) y(p, \alpha) T}{2}(c+p \alpha-c \alpha-2) \\
& |H|=\frac{-2 K}{T^{3}}\left(-b\left[(1-\alpha)+\frac{\alpha y(p, \alpha) T}{2}(c+p \alpha-c \alpha-1)\right]-b(1-\alpha)\right. \\
& \left.-\frac{\alpha b T y(p, \alpha)}{2}(c+p \alpha-c \alpha-1)-\frac{\alpha^{2} D(p) y(p, \alpha) T}{2}(c+p \alpha-c \alpha-2)\right) \\
& -\left(-\frac{D^{\prime}(p) h}{2}-\frac{c D^{\prime}(p) y(p, \alpha)}{2}-\frac{c D(p) y^{\prime}(p, \alpha)}{2}-\frac{(p-c) \alpha D^{\prime}(p) y(p, \alpha)}{2}\right. \\
& \left.-\frac{\alpha D(P) y(p, \alpha)}{2}-\frac{(p-c) \alpha D(p) y^{\prime}(p, \alpha)}{2}\right)^{2} \text {. }
\end{aligned}
$$

$|H|=V-W$ where,

$$
\begin{aligned}
V= & \frac{-2 K}{T^{3}}\left[-b\left[(1-\alpha)+\frac{\alpha y(p, \alpha) T}{2}(c+p \alpha-c \alpha-1)\right]-b(1-\alpha)\right. \\
& \left.-\frac{\alpha b T y(p, \alpha)}{2}(c+p \alpha-c \alpha-1)-\frac{\alpha^{2} D(p) y(p, \alpha) T}{2}(c+p \alpha-c \alpha-2)\right] \\
\text { and } W= & {\left[\frac{D^{\prime}(p) h}{2}+\frac{c D^{\prime}(p) y(p, \alpha)}{2}+\frac{c D(p) y^{\prime}(p, \alpha)}{2}+\frac{(p-c) \alpha D^{\prime}(p) y(p, \alpha)}{2}\right.} \\
& \left.+\frac{\alpha D(P) y(p, \alpha)}{2}+\frac{(p-c) \alpha D(p) y^{\prime}(p, \alpha)}{2}\right]^{2}
\end{aligned}
$$




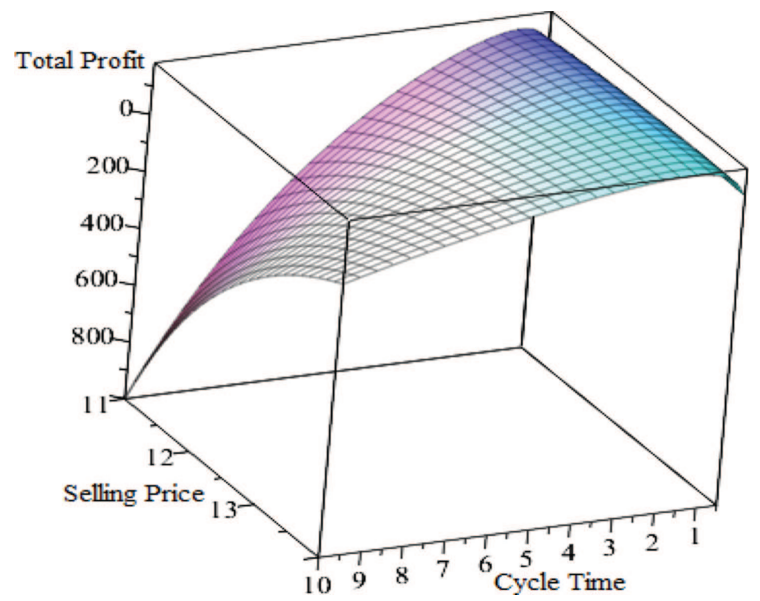

Figure B.1. Optimality of Total Profit w.r.t. $T$ and $p$.

Simplifying,

$$
\begin{aligned}
V= & \frac{4 K b(1-\alpha)}{T^{3}}+\frac{2 K}{T^{3}} \frac{\alpha y(p, \alpha) T}{2}(c+p \alpha-c \alpha-1)+\frac{2 K}{T^{3}} \frac{\alpha b T y(p, \alpha)}{2}(c+p \alpha-c \alpha-1) \\
& +\frac{2 K}{T^{3}} \frac{\alpha^{2} D(p) y(p, \alpha) T}{2}(c+p \alpha-c \alpha-2) \\
\text { and } \quad W= & {\left[\frac{-b h}{2}-\frac{(p-c) \alpha b y(p, \alpha)}{2}+\frac{(\alpha D(P)-c b) y(p, \alpha)}{2}+\frac{((p-c) \alpha+c) D(p) y^{\prime}(p, \alpha)}{2}\right]^{2} . }
\end{aligned}
$$

It can be analysed that due to nature of the parameters (i.e., $p>c, 0<\alpha<1, y(p, \alpha)<1,(y(p, \alpha))^{2} \ll 1, \alpha^{2} \ll$ $1, p>0, c>0, T>0)$, the value of $|H|$ comes out to be greater than zero as $V$ is greater than $W$. Since due to the complexity of the expression, term by term comparison is not feasible, Figure B.1 enforces the optimality.

Acknowledgements. All the authors express their gratitude to the editor and anonymous reviewers for their constructive comments that has helped in significantly shaping the manuscript.

Disclosure statement. No potential conflict of interest was reported by the authors.

\section{REFERENCES}

[1] S.P. Aggarwal and C.K. Jaggi, Ordering policies of deteriorating items under a permissible delay in payments. J. Oper. Res. Soc. 46 (1995) 658-662.

[2] A. Andriolo, D. Battini, R.W. Grubbström, A. Persona and F. Sgarbossa, A century of evolution from Harriss basic lot size model: survey and research agenda. Int. J. Prod. Econ. 155 (2014) 16-38.

[3] M. Bakker, J. Riezebos and R.H. Teunter, Review of inventory systems with deterioration since 2001. Eur. J. Oper. Res. 221 (2012) 275-284.

[4] S. Bardhan, H. Pal and B.C. Giri, Optimal replenishment policy and preservation technology investment for a non-instantaneous deteriorating item with stock-dependent demand. Oper. Res. 19 (2019) 347-368.

[5] Y. Daryanto, H.M. Wee and R.D. Astanti, Three-echelon supply chain model considering carbon emission and item deterioration. Transp. Res. Part E: Logistics Transp. Rev. 122 (2019) 368-383.

[6] S.C. Das, A.M. Zidan, A.K. Manna, A.A. Shaikh and A.K. Bhunia, An application of preservation technology in inventory control system with price dependent demand and partial backlogging. Alexandria Eng. J. 59 (2020) 1359-1369.

[7] P.M. Ghare and G.F. Schrader, An inventory model for deteriorating item for exponentially deteriorating items. $J$ Ind. Eng. 14 (1963) 238-243. 
[8] T.P. Hsieh and C.Y. Dye, A production-inventory model incorporating the effect of preservation technology investment when demand is fluctuating with time. J. Comput. Appl. Math. 239 (2013) 25-36.

[9] P.H. Hsu, H.M. Wee and H.M. Teng, Preservation technology investment for deteriorating inventory. Int. J. Prod. Econ. 124 (2010) 388-394.

[10] C.K. Jaggi and S.P. Aggarwal, Credit financing in economic ordering policies of deteriorating items. Int. J. Prod. Econ. 34 (1994) 151-155.

[11] C.K. Jaggi, K.K. Aggarwal and S.K. Goel, Optimal order policy for deteriorating items with inflation induced demand. Int. J. Prod. Econ. 103 (2006) 707-714.

[12] C.K. Jaggi, A. Khanna and M. Mittal, Credit financing for deteriorating imperfect-quality items under inflationary conditions. Int. J. Serv. Oper. Inf. 6 (2011) 292-309.

[13] C.K. Jaggi, A. Sharma and S. Tiwari, Credit financing in economic ordering policies for non-instantaneous deteriorating items with price dependent demand under permissible delay in payments: a new approach. Int. J. Ind. Eng. Comput. 6 (2015) 491-502.

[14] C.K. Jaggi, S. Tiwari and A. Shafi, Effect of deterioration on two-warehouse inventory model with imperfect quality. Comput. Ind. Eng. 88 (2015) 378-385.

[15] C. K. Jaggi, S. Tiwari and S.K. Goel, Credit financing in economic ordering policies for non-instantaneous deteriorating items with price dependent demand and two storage facilities. Ann. Oper. Res. 248 (2017) 253-280.

[16] C.K. Jaggi, P. Gautam and A. Khanna, Credit policies for deteriorating imperfect quality items with exponentially increasing demand and partial backlogging. In: Handbook of Research on Promoting Business Process Improvement Through Inventory Control Techniques. IGI Global (2018) 90-106.

[17] L. Janssen, T. Claus and J. Sauer, Literature review of deteriorating inventory models by key topics from 2012 to 2015. Int. J. Prod. Econ. 182 (2016) 86-112.

[18] A. Khanna, M. Mittal, P. Gautam and C.K. Jaggi, Credit financing for deteriorating imperfect quality items with allowable shortages. Decis. Sci. Lett. 5 (2016) 45-60.

[19] A. Khanna, P. Gautam and C.K. Jaggi, Inventory modeling for deteriorating imperfect quality items with selling price dependent demand and shortage backordering under credit financing. Int. J. Math. Eng. Manage. Sci. 2 (2017) 110-124.

[20] R. Li, H. Lan and J.R. Mawhinney, A review on deteriorating inventory study. J. Serv. Sci. Manage. 3 (2010) 117-129.

[21] G. Li, X. He, J. Zhou and H. Wu, Pricing, replenishment and preservation technology investment decisions for non-instantaneous deteriorating items. Omega 84 (2019) 114-126.

[22] N.K. Mandal, T.K. Roy and M. Maiti, Inventory model of deteriorated items with a constraint: a geometric programming approach. Eur. J. Oper. Res. 173 (2006) 199-210.

[23] A.H.M. Mashud, M.R. Hasan, H.M. Wee and Y. Daryanto, Non-instantaneous deteriorating inventory model under the joined effect of trade-credit, preservation technology and advertisement policy. Kybernetes 49 (2020) 1645-1674.

[24] A.H.M. Mashud, H.M. Wee and C.V. Huang, Preservation technology investment, trade credit and partial backordering model for a non-instantaneous deteriorating inventory. RAIRO-Oper. Res. 55 (2021) 51-77.

[25] J. Min, Y.W. Zhou and J. Zhao, An inventory model for deteriorating items under stock-dependent demand and two-level trade credit. Appl. Math. Modell. 34 (2010) 3273-3285.

[26] U. Mishra, An inventory model for controllable probabilistic deterioration rate under shortages. Evolving Syst. 7 (2016) 287307.

[27] U. Mishra, J. Tijerina-Aguilera, S. Tiwari and L.E. Cárdenas-Barrón, Retailer's joint ordering, pricing, and preservation technology investment policies for a deteriorating item under permissible delay in payments. Math. Prob. Eng. 2018 (2018).

[28] U. Mishra, J.Z. Wu, Y.C. Tsao and M.L. Tseng, Sustainable inventory system with controllable non-instantaneous deterioration and environmental emission rates. J. Cleaner Prod. 244 (2020) 118-807.

[29] S. Panda, S. Senapati and M. Basu, Optimal replenishment policy for perishable seasonal products in a season with ramp-type time dependent demand. Comput. Ind. Eng. 54 (2008) 301-314.

[30] S. Panda, S. Saha, N.M. Modak and S.S. Sana, A volume flexible deteriorating inventory model with price sensitive demand. Tékhne 15 (2017) 117-123.

[31] M. Pervin, S.K. Roy and G.W. Weber, Analysis of inventory control model with shortage under time-dependent demand and time-varying holding cost including stochastic deterioration. Ann. Oper. Res. 260 (2018) 437-460.

[32] J.I. Pitt and A.D. Hocking, Spoilage of stored, processed and preserved foods. In: Fungi and Food Spoilage. Springer, Boston, MA (2009) 401-421.

[33] S.S. Sana, Price-sensitive demand for perishable items - an EOQ model. Appl. Math. Comput. 217 (2011) 6248-6259.

[34] S. Saha and S.K. Goyal, Supply chain coordination contracts with inventory level and retail price dependent demand. Int. J. Prod. Econ. 161 (2015) 140-152.

[35] A.A. Shaikh, S. Tiwari and L.E. Cárdenas-Barrón, An Economic Order Quantity (EOQ) inventory model for a deteriorating item with interval-valued inventory costs, price-dependent demand, two-level credit policy, and shortages. In: Optimization and Inventory Management, edited by: N.H. Shah and M. Mittal. Assets Analytics. Springer (2020) 21-53.

[36] B.K. Shaw, I. Sangal and B. Sarkar, Joint effects of carbon emission, deterioration, and multi-stage inspection policy in an integrated inventory model. In: Optimization and Inventory Management, edited by: N.H. Shah and M. Mittal. Assets Analytics. Springer (2020) 195-208.

[37] S.R. Singh and S. Sharma, A global optimizing policy for decaying items with ramp-type demand rate under two-level trade credit financing taking account of preservation technology. Adv. Decis. Sci. 2013 (2013). 
[38] M. Ullah, B. Sarkar and I. Asghar, Effects of preservation technology investment on waste generation in a two-echelon supply chain model. Mathematics 7 (2019) 189.

[39] K.J. Wang and Y.S. Lin, Optimal inventory replenishment strategy for deteriorating items in a demand-declining market with the retailer's price manipulation. Ann. Oper. Res. 201 (2012) 475-494.

[40] T. Xiao and T. Xu, Coordinating price and service level decisions for a supply chain with deteriorating item under vendor managed inventory. Int. J. Prod. Econ. 145 (2013) 743-752.

[41] J. Zhang, Z. Bai and W. Tang, Optimal pricing policy for deteriorating items with preservation technology investment. J. Ind. Manage. Optim. 10 (2014) 1261-1277.

[42] J. Zhang, Q. Wei, Q. Zhang and W. Tang, Pricing, service and preservation technology investments policy for deteriorating items under common resource constraints. Comput. Ind. Eng. 95 (2016) 1-9.

\section{Subscribe to Open (S20) A fair and sustainable open access model}

This journal is currently published in open access under a Subscribe-to-Open model (S2O). S2O is a transformative model that aims to move subscription journals to open access. Open access is the free, immediate, online availability of research articles combined with the rights to use these articles fully in the digital environment. We are thankful to our subscribers and sponsors for making it possible to publish this journal in open access, free of charge for authors.

\section{Please help to maintain this journal in open access!}

Check that your library subscribes to the journal, or make a personal donation to the S2O programme, by contacting subscribers@edpsciences.org

More information, including a list of sponsors and a financial transparency report, available at: https://www. edpsciences.org/en/maths-s2o-programme 